\title{
Traversing the margins: Access to healthcare by Bakarwals in remote and conflict-prone Himalayan regions of Jammu and Kashmir
}

\author{
Veenapani Rajeev Verma*, Sumirtha Gandhi and Umakant Dash
}

\begin{abstract}
The study explores themes pertaining to access and utilization of healthcare embedded in Penchansky's framework, viz. availability, affordability, accessibility, acceptability and accommodation, in conjunction with Anderson's model of healthcare utilization amongst the transhumant pastoralist community of Bakarwals residing in Pir Panjal Range of Jammu and Kashmir. Bakarwals are fundamentally transhumant, but hordes of them sedentarized after militancy and conflict in the area reached its crescendo. Transhumants oscillate in space-time continuum, so it is imperative to conduct sample surveys due to non-existence of systematic surveillance data pertaining to health status and access of this group. The study employed a mixed method approach and took place during the reverse migration cycle from summer higher grazing pastures (dhoks) in the twin border districts of Poonch and Rajouri, comprising 250 structured questionnaire interviews coupled with 100 semi-structured interviews. Pir Ki Gali, Jammia Gali and Nurpur Gali transhumance routes were purposefully selected for discerning qualitative inquiry to yield cases with maximum information. A facility survey encompassing 12 primary health centres, three community health centres and two district hospitals was also conducted to ascertain supply-side factors in Bakarwal-concentrated areas. Results indicated lesser probability of utilization in higher pastures (dhoks) due to amalgamation of factors like geographical inaccessibility of modern medicine and cultural preference, but this is less pronounced in winter settlements and amongst the sedentarized. Demand for modern healthcare is also not commensurate with the supply for the same, exacerbated by non-availability of health professionals, drugs and poor quality of service provision found in the facility survey.
\end{abstract}

Keywords: Pastoralists, Transhumants, Healthcare access, Utilization

\section{Introduction}

Transhumance pastoralism is embedded in unique and diverse functional, social, cultural, spatial and environmental structures and institutions. Transhumance is a viable eco-social system which involves regular and cyclical seasonal movements of pastoralists along with their livestock between areas situated at different elevations and having different physical and climatic conditions. It describes the seasonal oscillation or periodic vertical shifts typically in mountain regions from winter to summer ranges. These societies do not establish permanent settlements; rather, they reside in temporary dwellings

\footnotetext{
*Correspondence: veenapani.verma1@gmail.com

Humanities and Social Sciences Department, IIT Madras, Chennai, India
}

located in different zones all year round. Transhumance pastoralism can be considered to be a human adaptation to marginal and spatially variant environments with a view to optimizing the use of natural endowments changing over time and varying space (Bhasin 2011). Transhumance is intertwined with and responsive to the seasonal rhythm. Semi-nomadism, another practice prevalent in the region, is a practice of some non-pastoral activities such as small-scale businesses and farming while retaining migration and livestock herding as their basic economy; part of the family moves with animals, while elderly people and children usually remain in the villages. There are a number of Himalayan tribes practising transhumance in the northern part of India; Bhotiyas in Uttarakhand; Changpas in Ladakh; Gaddis, 
Kanets, Kaulis and Kinnauras in Himachal Pradesh and Gujjar Bakarwals scattered over parts of Jammu and Kashmir. All these herders continue a long-standing tradition of migrating up to the alpine pastures of the high Himalayas for the summer and descending to the low-lying Himalayan foothills in the winter. Since independence of India, the pastoralists of Himalayas have faced a series of significant alterations stemming from external political and economic changes. These structural alterations have bought adjustments in many aspects of the traditional pastoral system, including their migratory cycle, local economy and social organization (Bhasin 2013). Transhumant pastoralists in India have a low human development index and high relative deprivation index, and to add to the caveat, they are often under-represented in government institutions and thus lack political empowerment. Health and poverty initiatives at the national level neglect these groups because of their geographic isolation/remoteness, poor communication, logistic requirements, uncertain civil status and perceived low priority. In return, mutual distrust between transhumant pastoralists and government structures poses a barrier to utilization of available services. The World Health Organization report on strengthening health systems, though considering most under-privileged populations, does not even mention mobile pastoralist populations (Zinsstag et al. 2006). However, in the Indian context, the National Commission for Denotified, Nomadic and Semi-Nomadic Tribes in its report proposed the identification of programmes required for their education, development and health, including improving the access to public health facilities (Ministry of Social Justice and Empowerment GoI 2008). The disparities in healthcare access are more pronounced amongst transhumant pastoralist tribes due to proximity and mobility issues exacerbated by affordability constraints, as these communities often lack the resources to travel long distances for treatment or to purchase certain prescribed drugs. More often, even in emergency cases, they have to walk long distances resulting in poor health outcomes.

This study explores the health accessibility issues for the Bakarwal tribe residing in the State of Jammu and Kashmir. Due to their strong social structure and symbiotic relationship with their environment, Bakarwals have been transforming their rich genetic potentialities into phenotypic realities for centuries (Kumar and Kumar 1998). Bakarwals adopt ethno-medicinal practice as the summer pastures (also known as dhoks locally) have a rich repository of biodiversity which is used to treat a multitude of chronic ailments like rheumatism, skin problems, high blood pressure, respiratory and reproductive disorders and non-chronic ailments like fever, common cold and cough, gastrointestinal problems and abdominal pains. In-depth ethno-botanical surveys of medicinal plants used by this community have been conducted across the State of Jammu and Kashmir and have revealed the importance of ethno- and traditional medicinal use by this tribe (Rashid 2013; Dangwal et al. 2014). However, the pronounced inaccessibility of modern medicine and institutional/formal care in the summer pastures translates to a heavy morbidity burden and also renders the patients non-compliant with treatment and loss of follow-up after the first contact.

\section{Ethnography}

The Bakarwals are transhumants who oscillate in the space-time continuum. The word Bakarwal connotes goat/sheep herders derived from the amalgamation of two terms, i.e. Bakri meaning 'goat/sheep' and wal meaning 'one who takes care of'. As an ethnic group, they emerged only since the beginning of the twentieth century from a conglomerate of other groups of pastoralists and peasants including Gujjars and Awans who migrated to Jammu and Kashmir from the Kunhar and Allai valleys in what is today the North West Frontier Province of Pakistan. These transhumant pastoralists are socially and geographically marginalized, who embark on their long journeys in convoys (kafilas) often thriving on social and relational capital. The area traversed by them is a contiguous succession of ranges and valleys encompassing Shiwaliks, Pir Panjal, Kashmir valley, Side valleys and the Greater Himalayan ranges. They ascend and descend ridges of myriad altitudes fording a plethora of hill torrents, streams and rivers and sometimes traverse a distance of more than $300 \mathrm{~km}$ in the high altitude terrain of northwestern Himalayas during their annual migration encumbered with their livestock. When the scorching heat of summer desiccates the pastures in the south, usable pastures are found in the north above $2745 \mathrm{~m}$ where melting snow leaves green pastures. Every year, they hike up to an elevation between 2940 and $4291 \mathrm{~m}$ above sea level, crossing different topographic zones (Khatana 1992).

The nature of their oscillation, the planning of annual and diurnal activities over space and through time, is to be perceived in the space-time continuum as their activities are correlated with two most important time cycles in the physical environment, i.e. spring and autumn migration. The functional community structure during the summer season is comprised of different deras (household units) who spread over pastures in all directions and construct makeshift houses on flat spaces available on slopes at fixed places. Deras are synonymous with the family, are the most dominant institution in their society and act as the centre of all major socio-economic, political and religious activities. 
Our investigations in this study only pertain to Gujjara Bakarwal transhumants who annually migrate, but there are other transhumant pastoralist groups of Gujjara residing in the State of Jammu and Kashmir such as Gujjara Baniharas or Dhodhi Gujjaras as well. Over the past two decades, Bakarwals have undergone a transformation as many have sedentarized owing to the conflict in the area, forest laws regulating the grazing land and inaccessibility of public goods like education and healthcare in higher pastures.

\section{Rationale}

Disaggregated data on indigenous people's health status and access are hard to find. Since this population is essentially invisible in the data collection, their health status vis-à-vis other groups is obscured. The dearth of serious research on access to healthcare amongst India's vulnerable transhumant pastoralist communities necessitated this study. One of the reasons for this is the lack of systematic surveillance data on the health status of these communities (Sheik-Mohamed and Velema 1999). Our study strives to address this gap by collecting primary data to analyse the factors impeding access to healthcare amongst the pastoral community of Jammu and Kashmir. Access to healthcare is concurrently influenced by demand- and supply-side constraints. Demand-side factors like people's willingness, socio-economic factors, affordability and ability generally operate at household, individual and community levels, whereas system-level determinants influence supply-side factors. Demandand supply-side factors are intertwined, and a nuanced approach would enable us to have a comprehensive understanding of the determinants of access to healthcare from different perspectives. Existing studies do not explore the causal impact of supply factors on healthcare use due to potential reverse causality. Endogeneity of healthcare service supply has only been addressed in two of the studies explaining determinants of healthcare seeking in low- and middle-income countries (Kumar et al. 2014; Anselmi et al. 2015). Despite this, very limited research has been done on assessing the combined impact of demand and supply variables on the use of healthcare services. This paper has made an attempt to integrate these demand- and supply-side factors to measure the access to healthcare services amongst the sedentarized as against the transhumant population.

\section{Objectives}

The objective is to investigate the barriers and enabling factors impacting the access by exploring different dimensions of access to healthcare amongst the Bakarwals. The study also endeavours to unravel the health-seeking behaviour of Bakarwals by analysing the determinants of the decision to use healthcare when ill. Further, the incidence of out-of-pocket and catastrophic expenditure on the household is calculated, and the factors/correlates influencing the catastrophic payments on healthcare are analysed.

\section{Study area}

The annual oscillation channel of Bakarwals passes over the mountainous region between Shiwaliks and greater Himalayas, traversing through Pir Panjal mountainous passes and the valley of Kashmir. The mobility patterns of Bakarwals were seriously perturbed by the Kashmir dispute because their traditional summer pastures in Gilgit and Baltistan became largely inaccessible after 1947. This study is conducted in the State of Jammu and Kashmir which is the northernmost state of India, nestled in the Himalayan range and bounded by the Line of Actual Control (boundary between India and Pakistan-administered Kashmir) and the international border with China. The State has been conferred with special autonomy under Article 370 of the Constitution of India. The presence of Scheduled Tribes is ubiquitous in this State, accounting for $11.9 \%$ of the total population of the state (Office of Registrar General and Census Commissioner GoI Ministry of Home Affairs 2011).

Field visits were made in various pastures in close proximity of LOC and the international border with Pakistan in the districts of Rajouri and Poonch. Healthcare infrastructure in the focus districts comprises one district hospital, three community health centres and 17 primary health centres in Poonch, whereas there are one district hospital, eight community health centres and 30 primary health centres in Rajouri. The topography of these districts is hilly and mountainous. Barring a few low-lying areas. These are the remotest districts of Jammu and Kashmir, are conflict-prone areas with heavy military deployment and are bearing the brunt of militancy and cease-fire violations due to porous borders over the last few decades.

\section{Methodology \\ Sampling design and data collection}

The study employed a mixed methodology via a concurrent triangulation approach. The main purpose of this design is to offset the weakness inherent within one method with the strengths of the other method (Creswell et al. 2006; Teddlie and Tashakkori 2003). The study adopted a survey method conducted during the 'reverse migration' cycle from summer higher grazing pastures (dhoks) , and included 250 structured household schedules. These schedules incorporated both sedentarized and migratory populations with a sample size of 150 and 100 households, respectively. Mountain passes are the traditional migration routes with a fixed schedule of departures. Three transhumance routes, i.e. 
Pir Ki Gali Pass, Jamiyan Gali Pass and Nurpur Pass, were selected to obtain qualitative information pertaining to barriers for access to higher pastures. Maximum information was collected through 100 semi-structured schedules. A snowball sampling technique of identifying households was used for quantitative information, and samples for qualitative inquiry based on willingness to participate were selected. Further, to corroborate the quantitative findings, 10 focused group discussions were conducted with the help of Jirgas (Tribal Panchayats). Discussions and interviews were conducted in the Gojri local dialect, and saturation and redundancy of information were used to frame the discussion. Also, a facility survey encompassing 12 primary health centres, three community health centres and two district hospitals was conducted, coupled with administrative data from government offices to unravel the impact of supply-side factors on access and utilization. The norms considered for minimum service coverage, human resource, equipment and infrastructure were taken to be symptomatic of the Indian Public Health Standards (IPHS) and were used to derive the dimension score and overall health facility readiness score.

\section{Framework and estimation}

Descriptive statistics and instrumental variable probit regression ${ }^{1}$ were used to measure the aforementioned objectives. Descriptive statistics encapsulate a brief summary of the entire population and findings on themes exploring the healthcare access and utilization nuances. The study is embedded in the conceptual framework of Penchansky which identifies five dimensions of access, viz. availability, affordability, acceptability, accessibility and accommodation (Penchansky and Thomas 1981). Our framework included all these dimensions through which access can be evaluated directly instead of focusing on utilization of care as a proxy for access. The details of variables and methodological constructs are provided in Tables 1 and 2 of Additional file 1. Further, the probit regression model was used to estimate the effect of both demand- and supply-side covariates on the probability of utilization of healthcare services. The covariates were selected through augmentation of Anderson's framework of healthcare utilization. This framework assumes that healthcare utilization is influenced by predisposing factors, enabling factors and need-based factors (Andersen 1995), which was modified by incorporating the supply-side factors in explaining the decision to seek care (Additional file 1). According to Grossman's model of human capital (Grossman 2000), individual demand for healthcare is closely linked to the random utility model, which states that an individual maximizes his utility by trading off between his preference for health and consumption of other goods; utility function can therefore be formulated as:

$$
U_{i}=\left(H_{i}, Z_{i}\right)
$$

where $U_{i}$ denotes the level of satisfaction/utility, $H_{i}$ denotes health status by seeking care and $Z_{i}$ reflects other goods consumed by an individual. Using the latent variable approach, the observed decision to seek care is defined as a function of the observed determinants of healthcare demand and supply:

$$
\begin{aligned}
& Y_{i}^{*}=\begin{array}{l}
U_{i}^{S 1}-U_{i}^{S 0}=\alpha_{1}+\beta_{1} X_{i, c l}+\beta_{2} \mathrm{QS}_{i}+\beta_{3} D_{i, c l} \\
+\beta_{4} \mathrm{HRS}_{i}+\varepsilon_{i, c l}
\end{array} \\
& S_{i}=\left\{\begin{array}{l}
1, \text { if } Y_{i}^{*} \geq 1 \\
0, \text { if } Y_{i}^{*} \leq 0
\end{array},\right.
\end{aligned}
$$

where $Y_{i}^{*}$ represents the difference between the utility from seeking $\left(U_{i}^{S 1}\right)$ and utility from not seeking care $\left(U_{i}^{S 0}\right)$; here, $S_{i}$ is a dummy taking the value of 1 if an individual is better off when seeking care from a public provider and 0 otherwise. $\mathrm{QS}_{i}$ measures the perceived quality of care, and $\mathrm{HRS}_{i}$ is the health facility readiness score. In this study, the effect of health service availability and readiness score on the decision to use healthcare when ill is computed using an instrumental variable approach. The health service readiness score is calculated via amalgamation of average scores across five dimensions, i.e. (a) physical infrastructure and amenities, (b) human resources, (c) equipment, (d) drugs and consumables and (e) service provisioning. However, the allocation of human resources, equipment and infrastructure could be disproportionately higher for health facilities where service use is higher, insinuating the endogeneity problem which is rectified using the instrumental variable approach. Existing studies do not explore the causal impact of supply factors on healthcare use due to potential reverse causality. Endogeneity of healthcare service supply has only been addressed in two of the studies explaining determinants of healthcare seeking in low- and middle-income countries (Kumar et al. 2014; Anselmi et al. 2015). $D_{c l}$ are the dummies representing time taken to reach the nearest facility and the degree of remoteness of place proxied by the availability of transportation within a $2-\mathrm{km}$ radius. $X_{i}$ is a vector of characteristics explaining predisposing, enabling and need-based factors influencing the utilization. Derived from empirical specification in Eq. (1), the probability of seeking care is elucidated using a probit model:

$$
\begin{aligned}
\operatorname{Pr}\left(S_{i}=\frac{1}{X_{i}}, \mathrm{QS}_{i}, D_{i, c l}, \mathrm{HRS}_{i}\right)= & \Phi\left(\alpha_{1}+\beta_{1} X_{i, c l}+\beta_{2} \mathrm{QS}_{i}\right. \\
& \left.+\beta_{3} D_{i, c l}+\beta_{4} \mathrm{HRS}_{i}+\varepsilon_{i, c l}\right)
\end{aligned}
$$

The endogeneity of the health facility readiness score is tested using the Wald test of exogeneity where a 
significant rho and the Wald test rejected the null hypothesis of exogeneity, suggesting endogeneity of the health facility readiness score. Following this, in this study, frequency of monitoring and supervision of the health facilities by senior officials and supervisory staff is used as the instrument for the health facility readiness score. The choice of instrument emanates from the fact that it has no direct effect on individual decision to seek care other than through improved readiness and responsiveness of health facilities.

$$
\begin{aligned}
& Y_{i}^{*}=\alpha_{1}+\beta_{1} X_{i, c l}+\beta_{2} \mathrm{QS}_{i}+\beta_{3} D_{i, c l}+\beta_{4} \mathrm{HRS}_{i}+\varepsilon_{i, c l} \\
& \mathrm{HRS}_{i}=\gamma_{0}+\gamma_{1} X i, c l+\gamma_{2} \mathrm{QS} i+\gamma_{3} D i, c l \\
& +\gamma_{4} \mathrm{HM} 1+U i \\
& S_{i}=\left\{\begin{array}{l}
1, \text { if } Y_{i}^{*} \geq 1 \\
0, \text { if } Y_{i}^{*} \leq 0
\end{array},\right.
\end{aligned}
$$

$\mathrm{HM}_{i}$ is the average monitoring and supervision visits made by the seniors like medical officer, lady health visitor, block medical officer and chief medical officer in the last six months prior to the survey in the facility. The strength of the instrument is tested using the $F$ test statistic.

Further, to elucidate the incidence and determinants of catastrophic health expenditure, total household consumption expenditure and a household's capacity to pay proxied by non-subsistence, non-food expenditure is considered. The share of out-of-pocket health expenditure in the household's total expenditure is estimated to define the catastrophic health expenditure:

$$
\begin{aligned}
& S_{1}=\frac{\mathrm{HE}_{i}}{\mathrm{TE}_{1}} \times 100 \\
& S_{2}=\frac{\mathrm{HE}_{i}}{\mathrm{TE}_{2}} \times 100
\end{aligned}
$$

where $\mathrm{HE}_{i}$ denotes a household's out-of-pocket expenditure on healthcare, $\mathrm{TE}_{1}$ represents household's total consumption expenditure and $\mathrm{TE}_{2}$ represents a household's total non-food consumption expenditure. $S_{1}$ is a binary outcome variable coded as outcome 1 when out-of-pocket expenditure on health as a percentage of a household's total consumption expenditure exceeds the threshold of $10 \%$ and 0 if otherwise. Similarly, $S_{2}$ is dichotomized and coded as 1 if healthcare expenditure exceeds $40 \%$ of a household's non-food expenditure. As inpatient and outpatient expenditures were collected for different recall periods of one year and one month respectively, they were converted into the same recall period of one month to calculate out-of-pocket payments and determine whether catastrophic health expenditures have occurred or not. Further, the logit model was employed to assess the determinants of catastrophic health expenditure in households. Therefore, a battery of estimation techniques is used to enable the analysis.

\section{Results}

Figure 1 represents the general characteristics of healthcare seeking by Bakarwals. The morbidity amongst the migrants was reported to be $28 \%$, while it was $8 \%$ points lower for the sedentarized. Out of the total migrants who reported illness, only $68 \%$ of them sought care and $32 \%$ did not seek either of the formal or informal care, resorting to self-treatment or neglect. The percentage of the sedentarized however, who resorted to no care is far less than that of migrants. Also, there is substantial divergence with respect to seeking formal care between migrants and the sedentarized, as a greater percentage of the sedentarized population sought care from formal providers as compared to migrants, due to larger time-distance constraints for migrants to access the institutional care.

The choice of providers for the pastoralists is reflected in Table 1 which reveals that for both migrants and the sedentarized population, public healthcare facilities are the preferred choice for inpatient care with more than three fourths of the population getting admitted in public hospitals. However, the trend is reversed for ambulatory care where around 42 percentage of migrants and 32 percentage of the sedentarized visit private providers for outpatient care; a significant proportion of people also visit informal providers like pharmacies and traditional healers. Whereas, for the sedentarized group, due to equal proximity to public facilities and private providers, public facilities are more preferred as compared to migrants. This thereby suggests that the gains of public provision are being reaped by the sedentarized pastoralists, due to the accessibility issue. However, the preference of private providers is still high amongst sedentarized non-migrants due to the non-availability of desired services and abysmal standards of quality in public facilities.

Further, Fig. 2 represents the perceived barriers to healthcare utilization amongst Bakarwals. Converging with the conjecture that accessibility poses a major barrier to seek care amongst the migratory population, 75\% of them stated that long geographical distances are an impediment to utilization. Accessibility does not necessarily translate to availability, as $48 \%$ migrants indicated that availability of staff/drugs/infrastructure even when the facility is geographically accessible poses a great challenge. However, the unavailability concern is more prominent $(64 \%)$ for the sedentarized as the geographical time-distance barrier is lower for them, indicating relative ease of accessibility due to the community surviving on the brink of the margin. Healthcare expenditure remains an Achilles heel for both groups with 


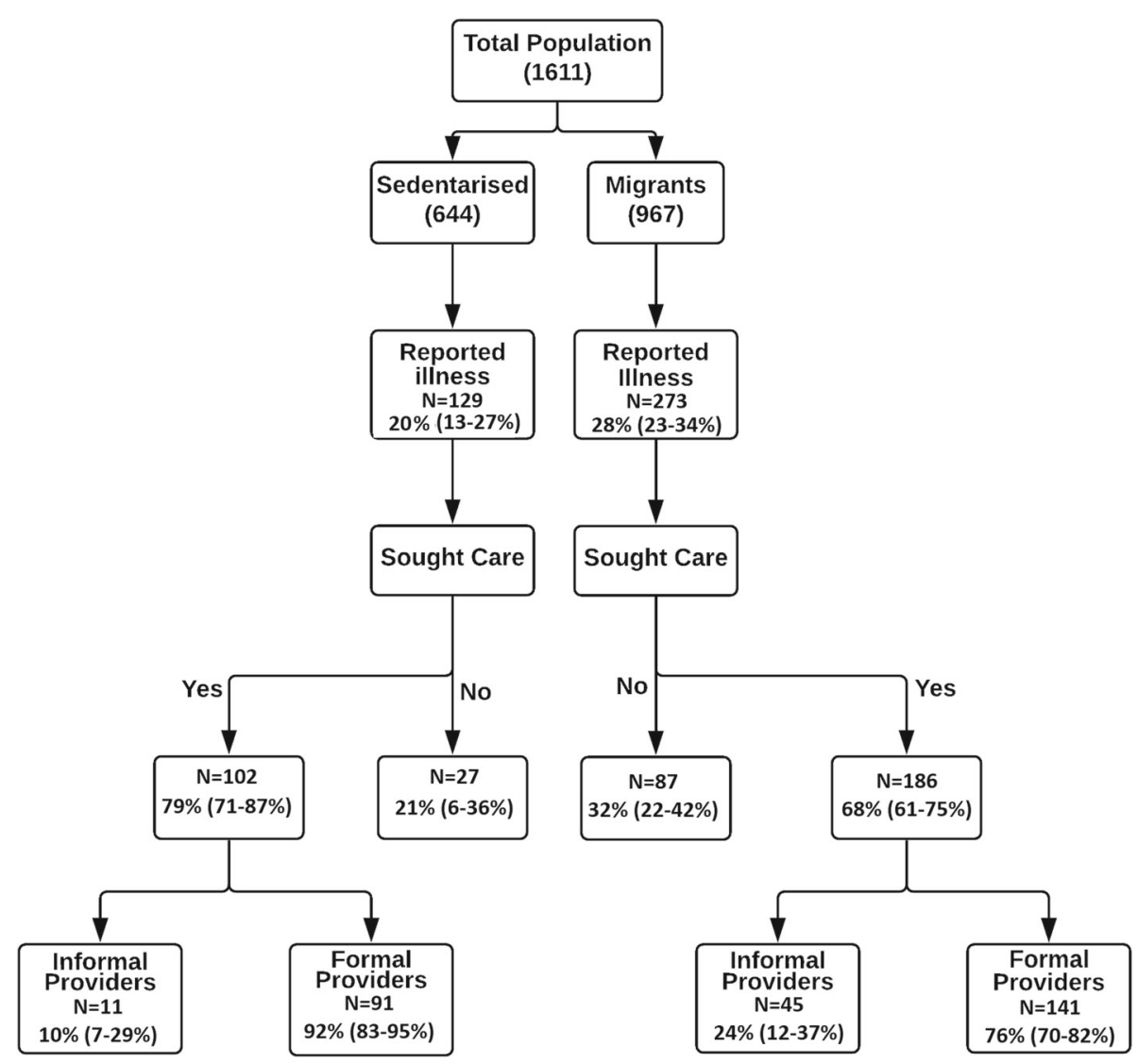

Fig. 1 General characteristics of seeking care amongst the Bakarwals

nearly half the population stating it as a barrier. However, acceptability issues in terms of cultural compatibility, staff behaviour and perceived quality is more pronounced among migrants vis-à-vis sedentarized. Whereas accommodation barriers subsume inconvenient hours, contact constraints, organizational structure, appointment issues etc.

\section{Accessibility}

Accessibility can be defined as the factors intervening between the perception of need and the realization of utility (Joseph and Phillips 1984). 'Effective accessibility' to medical services reflects an individual/family's 'ability, mobility and time to reach a service' once a need has been established by a potential health service user (Phillips et al. 1990), which can be distinguished from 'potential accessibility' which simply implies the existence of a service, regardless of whether it is 'effectively accessible'. Importantly, time, effort and costs required in seeking and using health services should be compensated for by the expected benefits of doing so. McKinlay (1972) identified groups of accessibility factors impeding the utilization of health services at the individual/family level; in addition to geographical factors and factors related to the organization of health service delivery, economic and socio-cultural determinants of utilization were also suggested.

Geographical access to facilities in Jammu and Kashmir is highly impeded due to topography and agro-climatic conditions in the area. It was revealed that user cost did not inhibit the utilization of health services as much as the distance-time problems in reaching

Table 1 Choice of providers for inpatient and outpatient care amongst Bakarwals

\begin{tabular}{|c|c|c|c|c|c|}
\hline Group & Level of care & Public (95\%Cl) & Private $(95 \% \mathrm{Cl})$ & Traditional $(95 \% \mathrm{Cl})$ & Pharmacy $(95 \% \mathrm{Cl})$ \\
\hline \multirow[t]{2}{*}{ Migrants } & Inpatient & 78.76 (71 to 86$)$ & 17.69 (11 to 25$)$ & 3.54 (0.18 to 7.03$)$ & - \\
\hline & Outpatient & 10.09 (7 to 13$)$ & 42.69 (38 to 48 ) & $10.82(7$ to 14$)$ & 36.4 (31 to 42 ) \\
\hline \multirow[t]{2}{*}{ Sedentarized } & Inpatient & 81.31 (73 to 89) & 17.58 (11 to 25$)$ & 1.11 ( -0.8 to 3$)$ & - \\
\hline & Outpatient & 30.01 (22 to 38 ) & 32.12 (24 to 40$)$ & $10(5$ to 15$)$ & 27.87 (20 to 35 ) \\
\hline
\end{tabular}




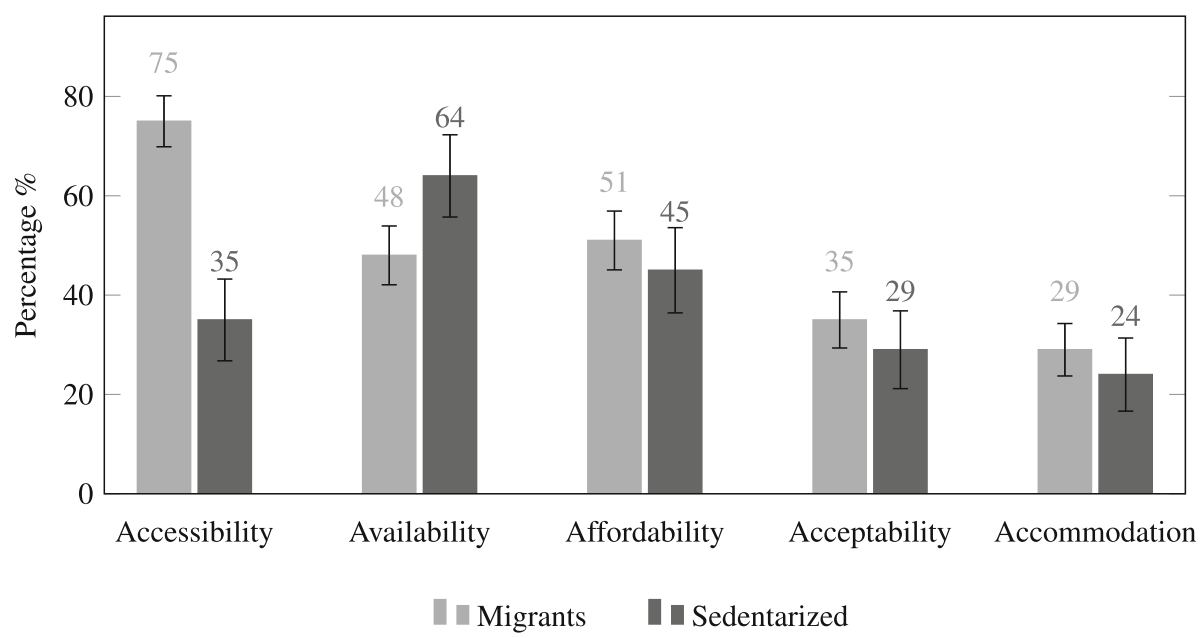

Fig. 2 Perceived barriers to access amongst the Bakarwals (error bars represent 95\%Cl)

government facilities. Moreover, 'time coupling' influences which services are most accessible. The mobile groups reveal that they are unsure about the day and opening and closing times on which health sub-centres and primary care centres would be open. These facilities operate upon discretion and convenience of health workers not adhering to stipulated timings leading to inconvenience for community to reach the centres on time. Thus, they do not rely on these facilities which have daytime working hours only providing intermittent care and the mobile groups instead prefer district hospitals and community health centres, even for primary care. Also, these groups do not seek care at the onset of disease but seek formal care at the progression of disease and thereby prefer travelling a longer distance to a tertiary care hospital in order to circumvent the limitations of small facilities. Geographical and time-related accessibility problems are compounded when the pastoralists migrate to summer pastures (dhoks) which are invariably more remote areas with no motorable roads up to 100 $\mathrm{km}$ and they often do not seek formal ambulatory care. Table 2 illustrates that the difference in distance travelled to health care facilities in summer pastures by migrants is much more pronounced than that travelled by them in winter pastures and by the sedentarized population. The absence of a road network and infrastructure

Table 2 Mean distance $(\mathrm{km})$ and time taken to reach the nearest healthcare providers

\begin{tabular}{llllll}
\hline Provider accessed & \multicolumn{2}{l}{ Winter settlement } & & \multicolumn{2}{l}{ Summer settlement } \\
\cline { 2 - 3 } & Distance & Time & & Distance & Time \\
\hline Public & 10 & $2.5 \mathrm{~h}$ & & 100.3 & $20 \mathrm{~h} / 2$ days \\
Private & 9.5 & $2.4 \mathrm{~h}$ & & 98.7 & $20 \mathrm{~h} / 2$ days \\
Traditional healing & 2 & $30 \mathrm{~min}$ & 0.5 & $15 \mathrm{~min}$ \\
Pharmacy & 8 & $1.1 \mathrm{~h}$ & & 50 & $8 \mathrm{~h} / 1$ day \\
\hline
\end{tabular}

in summer pastures creates a double whammy and raises the barriers to seeking care as patients have to resort to the only alternative of walking in a difficult terrain and aggravating their health condition.

The field narratives are replete with concerns and distress which they have to face in emergency situations. The preference for the traditional medicine or self-care and a disparaging attitude towards modern medicine are mostly a consequence of geographic inaccessibility of formal care and relative accessibility of medicinal herbs and traditional healers practising ethno-medicine.

We harness the medicinal herbs and often administer the vaccines ourselves in Dhoks due to impregnable physical and perceived psychological distance to the facility. We know the art of using different parts of same medicinal plant like roots, shrubs, leaves to treat various ailments. (Elderly man, Bakarwal)

The journey to the healthcare provider for patients and attendants is fraught with further obstacles, owing to the rudimentary infrastructure in the area. More often, there is the absence of a road network; sometimes, there are just unmotorable bridle paths available. Also, people living very close to the border are devoid of mobile phone networks to contact in case of emergencies.

In case of emergency, we carry the patients in a palanquin trudging the strenuous terrains to reach motorable road. Very serious patients often do not make it to the end of journey. (Head of the family, Bakarwal)

\section{Availability}

The organizational capacity of health service delivery to respond to people's need is manifested in the availability 


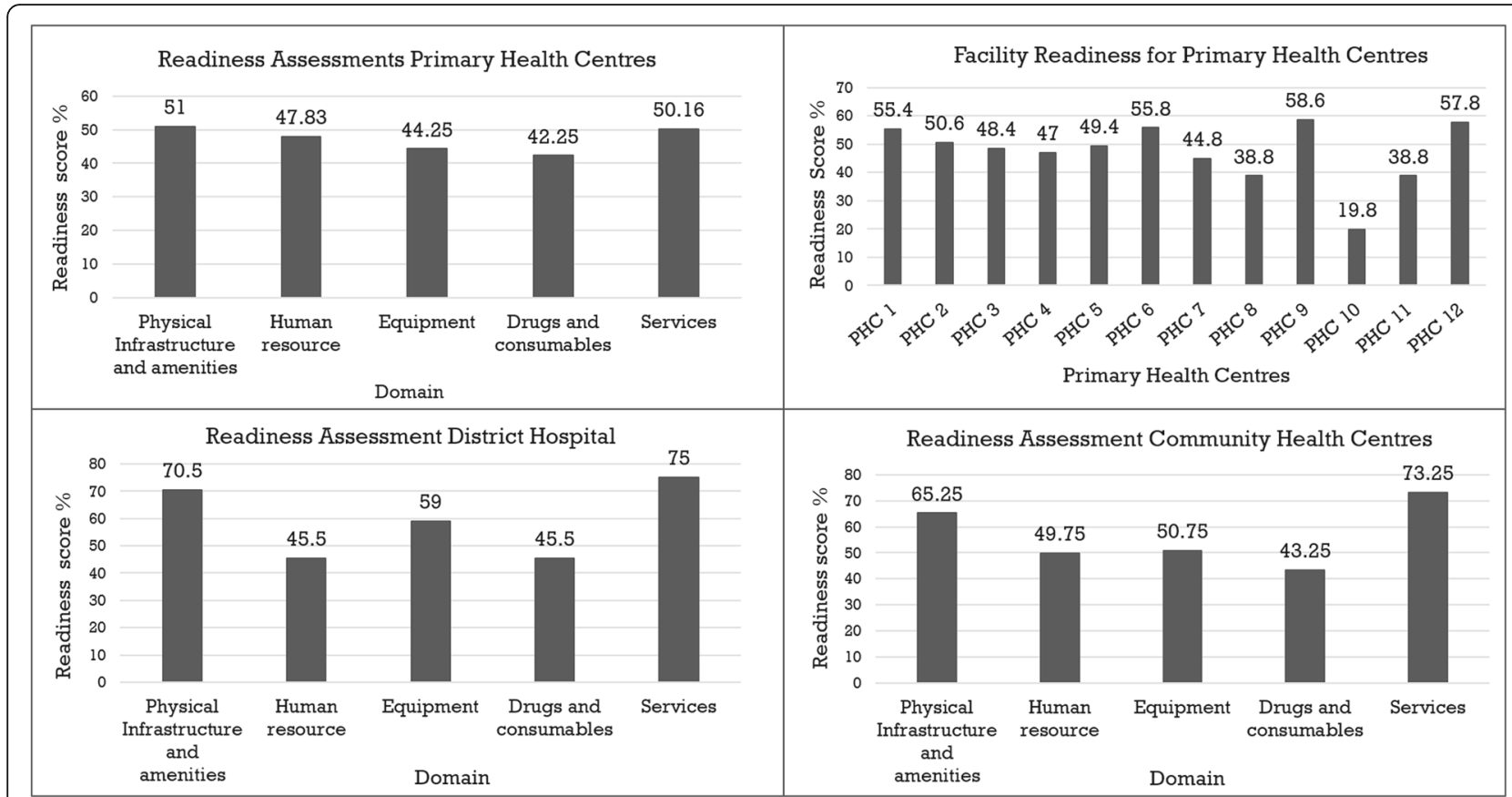

Fig. 3 Service availability and health facility readiness scores of the facilities surveyed

of healthcare infrastructure in an area. Decrepit standards in the service availability and readiness are resonating in Fig. 3 , as explained by low health facility readiness scores. Overall, primary health facilities had a mean readiness score of $47.1 \%$ with overall scores ranging from an abysmally low score of 19.8 to $58.6 \%$ averaging across five dimensions. On average, primary health facilities had $51 \%$ of physical infrastructure and amenities available (55 tracer items including condition of building, available facilities, operation theatre, lab infrastructure, communication facilities). Health workforce shortage was found to be the greatest predicament inadvertently increasing the barriers, as $47.8 \%$ of human resources were in place indicating a shortage of $52.2 \%$ as against the norms. Also, the score encumbering the availability of equipment was found to be unsatisfactory at $44.25 \%$ (56 tracer items encapsulating delivery and labour room equipment, newborn care equipment, equipment for eye care and vision testing, cold chain equipment, reagents, etc.). There was also shortage of medicines and consumables owing to the supply-side constraints in the facilities as only $42.2 \%$ of the medicines from the essential drug list were available on the date of survey (51 tracer drugs including anti-infective medicines, drugs for cardio-vascular disease, vaccines, contraceptives). Also, only half of the range of services recommended in the guidelines were available in the centres $(40$ different services ranging from Maternal and Child Health care $(\mathrm{MCH})$, family planning, childcare immunization, disease surveillance to epidemics control). The performance of secondary and tertiary care facilities is also dismally low, especially in terms of service provision and physical infrastructure and amenities with only one third of the norms being satisfied. For drugs and consumables, along with other dimensions, the score is less than $50 \%$, implying substandard service provision.

The empirical findings presented above are congruent with the narratives encountered in the discussions with the pastoralists and service providers who expressed their discontent over availability. Many of the facilities on the date of survey were found closed due to the nonchalant behaviour of staff and lack of monitoring and supervision, due to which patients often are forced to purchase over-the-counter drugs from nearby pharmacies. Even if the facility is open, shortage of equipment, drugs and workforce leads these facilities to refer even the primary management cases to the tertiary providers.

The condition of this building is dilapidated and there is not even a refrigerator to stock the vaccines. The infrastructure is not amenable to childbirth as it's not equipped with labour table or forceps etc. for assisted delivery. We conduct emergency deliveries in deplorable conditions and prefer to refer most of the cases to district hospital. (Health worker, primary health centre)

People also reported and exhibited disgruntlement at the vacancies of sanctioned posts and excessive 
absenteeism of health workers from the facilities, forcing them to seek care from private providers or at a distant location, thereby amplifying expenditures and inconvenience. Also, narratives voicing malpractices and informal payments by the health workers were ubiquitous.

We walk long distances in hilly winding kutcha (muddy and unbridled) roads to reach health centre but health worker often tells us to visit her residence where she stocks government supply of medicines and charges user fee on drugs at her own discretion. As far as doctor is concerned, there's none in this facility for last 20 years.

(Bakarwal patient, 35 years old)

\section{Affordability}

Almost every individual surveyed incurred out-of-pocket expenditure (OOPE) on treatment both for inpatient and outpatient care. None of the households was covered under a financial risk protection scheme which means zero insurance coverage rendering households vulnerable to health shocks. A significant amount of OOPE was incurred on transportation for both for inpatients and outpatients, comprising one third of the total cost incurred (Fig. 4). Whereas, in tandem with national and state overall figures, a huge amount of expenditure goes to the drugs and consumables whereas diagnostic charges are also high for these communities. Also, due to the large physical distance from their abode to the point of care and lack of public transportation and ambulances for referrals, lodging and food expenses also escalate in the case of inpatients. Consultation charges on the other hand are twice as high for outpatients as compared to inpatients, probably due to the high user fee charged by private providers, since seeking care from
Table 3 Incidence of catastrophic expenditure at different levels of threshold

\begin{tabular}{lll}
\hline $\begin{array}{l}\text { Proportion of total } \\
\text { expenditure }\end{array}$ & $\begin{array}{l}10 \% \text { threshold } \\
(95 \% \mathrm{Cl})\end{array}$ & $\begin{array}{l}40 \% \text { threshold } \\
(95 \% \mathrm{Cl})\end{array}$ \\
\hline Migrants & $33.2(26$ to 41$)$ & $26.6(19$ to 35$)$ \\
Sedentarized & $30.1(19$ to 41$)$ & $25.7(15$ to 37$)$ \\
\hline
\end{tabular}

private providers outweighs public providers for outpatient care. Further, Table 3 reveals that incidence of catastrophic expenditure at $10 \%$ threshold is very high, i.e. $33.2 \%$ for migrants and $30.1 \%$ for the sedentarized population; this exceeds the national and state average for catastrophic expenditure. Even at $40 \%$ threshold as an indicator of capacity to pay, the figures are high, indicating alarming figures and a need for financial risk protection amongst these groups.

The affordability predicament gets weighed in during the curfews and politically volatile times in the area, leading to complete shutdown and perturbed treatment for patients.

Due to unrest in the Kashmir valley, the access to even private providers was difficult, my brother had to be taken to hospital urgently, after a long tedious journey; we could find only one private hospital which charged exorbitant price for treatment. Even consultation fee by doctor is four - five times the normal rate during curfews. (Middle-aged man, Bakarwal)

The journey and stay in the inaccessible summer pastures are particularly detrimental to the health of Bakarwals, especially those suffering from chronic ailments with sustained need for medicines and follow-ups. It is necessary for them to buy large stocks of medicines before the migration cycle which they often cannot afford as a one-time bulk payment.

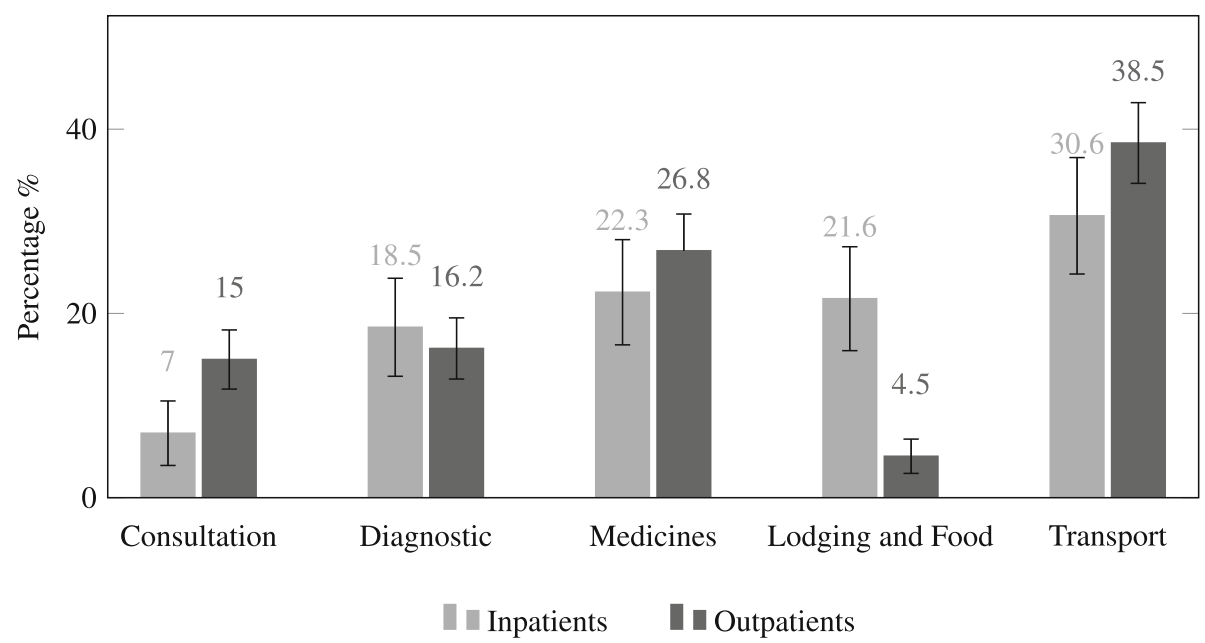

Fig. 4 Components of out-of-pocket expenditure for inpatient and outpatient care (error bars represent 95\%Cl) 
I am a 70 year woman with chronic joint pain still walking for 350 miles back from Dhok. Before embarking on journey to summer pasture, I went to the pharmacy to purchase stock of medicines but they were too expensive that I couldn't afford it. Now after this noncompliance to medication and arduous journey thereafter has deteriorated my condition. (Elderly woman, Bakarwal)

\section{Acceptability}

Acceptability is often a neglected dimension of access to healthcare and is pertinent to be considered for patient-centric healthcare, especially in trans-cultural societies. Acceptability is often a poorly conceptualized dimension, but in this study, we used it to examine social acceptability from a user's perspective. In this view, acceptability can be seen as 'the relationship of clients' attitudes about personal and practice characteristics of providers to the actual characteristics of existing providers, as well as to provider attitudes about acceptable personal characteristics of clients' (Penchansky and Thomas 1981). The term acceptability was used to describe consumer reaction to personal characteristics of providers like sex or ethnicity, to the type of facility, to the religious affiliation of the facility or provider or to the neighbourhood of the facility. Providers, in turn, were described as having attitudes with regard to preferred attributes of clients or financing mechanisms, showing for instance unwillingness to serve welfare patients. Figure 5 elucidates the range of acceptability issues faced by the community. The majority of the people (42\%) cited mistrust of the ability of providers, reflecting a quality issue as the major detrimental factor to utilization, followed by complaints regarding the negligence (37.2\%) and nonchalant attitude of the provider distorting the degree of fit. However, a significant proportion of people had issues with the behaviour of staff and said that they are not being reassured and comforted or properly communicated about their illness and symptoms. There is also some bias against this particular community as reflected in the attitude of the workforce as $18 \%$ of people complained that they were being mistreated by the staff.

When a Bakarwal comes to the health centre, staff treats him differently. When the doctor comes to examine him, he won't even touch him. They don't consider him a human being and compares him with cattle. They will say this is a Bakarwal who is unhygienic and stinky. Why don't they promote hygiene and sanitation education by asking nicely? (Sarpanch, Bakarwal)

Also, the belief in ethno-medicine and traditional healing also snowballs into distrust of modern medicine. Religio-cultural values and beliefs are ubiquitous in this community, and people prefer to visit a peer (spiritual healer) especially when they perceive that they are being possessed by spirits or jinn. Thus, they resort to religious authority for diseases attributed to affliction by black magic manifested in the form of unexplained physical symptoms and psychological ailments.

Our Hakims are more skilled than your doctors. They can use the same plant as remedy for different ailments. My daughter was suffering from an evil eye but we couldn't reckon it and got duped by doctors as they misdiagnosed it for epilepsy. We spent fortune on her treatment in hospitals but there was no relief. Finally, upon counselling of elders we made a journey to peer baba and he warded off the evil spirits. He gave a lotion laced with magical incantations to purge my daughter of evil possessions. Mashallah she's feeling better now. (Father of a Bakarwal girl)

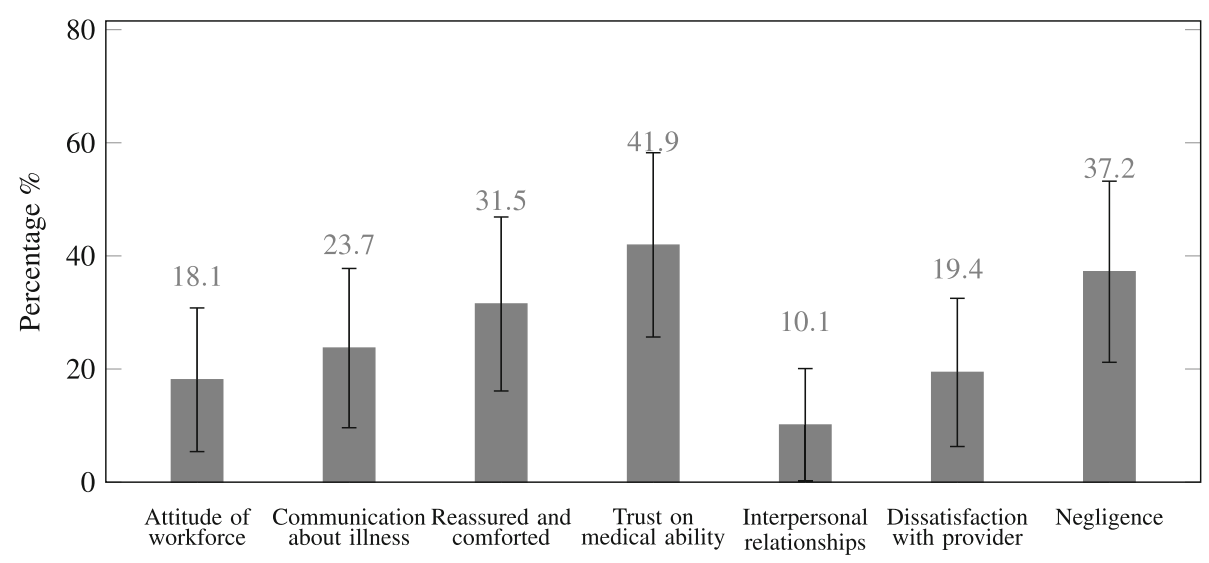

Fig. 5 Acceptability barriers amongst the Bakarwals (error bars represent 95\%Cl) 


\section{Accommodation}

Accommodation denotes the relationship between the manner in which supply-side resources are organized to accept a client's preferences and a client's abilities to accommodate these factors and their perception of its appropriateness (Penchansky and Thomas 1981). Satisfaction and accommodation are synonymous, and they are reflective of process quality of service delivery. These accommodation barriers are highly salient to patient experiences and are indispensable to patient-centred access to healthcare. Figure 6 depicts the barriers faced by the community with respect to accommodation. Around three fourths of the survey respondents reported dissatisfaction due to the opening hours of the facility, as it was inconvenient for them to seek care during those hours. Ineffective communication with the provider due to the absence of a communication infrastructure was reported as a hindrance by $17.6 \%$ of the people. Egregious absence of staff members from facilities, particularly in primary care facilities, was found during the survey. Also, the absence of round-the-clock services provided in these facilities due to restricted opening time depletes the trust and reliance on them. Moreover, the perception of service quality delivered in these facilities is abysmally low, rendering them unpopular and leading to bypassing of first referral units.

We don't visit the government health facility anymore as we are assured that either facility will be closed/ services won't be available upon our arrival, leaving us exasperated after a long journey. (Bakarwal patient, 50 years old)

Accommodations targeting the needs of a specific population evolve as health systems search for solutions to challenges of healthcare provision to their diverse patients. Coverage of services commensurate with the needs of remote and hard-to-reach groups requires tweaking the organizational structure and delivery mechanism. Pastoralists often seeking care in outlying areas can be accommodated and integrated in the mainstream system through outreach services and mobile camps. However, such worker-client encounters amongst this population group were found to be meagre. It was also narrated by community leaders that health workers force them to come to the facility for immunization even though there is a provision of outreach programmes via the Indhradhanush mission in summer season.

I have never encountered any health worker coming to our dhoks, I carried my 6 month's son for vaccination and reached the facility after 3 hour journey by $3 \mathrm{pm}$, but health worker had already left and the centre was locked so now I have to wait for another month for vaccination day. (Father of Bakarwal)

\section{Instrumental variable probit regression results}

The results for instrumental variable probit regression are represented in Table 4 which illustrates the marginal effects of determinants of healthcare utilization on the probability of seeking care in a government facility. Healthcare utilization is explained by the amalgamation of demand and supply which are essentially a consortium of independent variables ranging from predisposing, enabling and need-based factors and also from the factors connoting the supply-side and institutional constraints. Existing studies do not explore the causal impact of supply factors on healthcare use due to potential reverse causality. Endogeneity of healthcare service supply has only been addressed in two of the studies explaining determinants of healthcare seeking in lowand middle-income countries (Kumar et al. 2014; Anselmi et al. 2015).

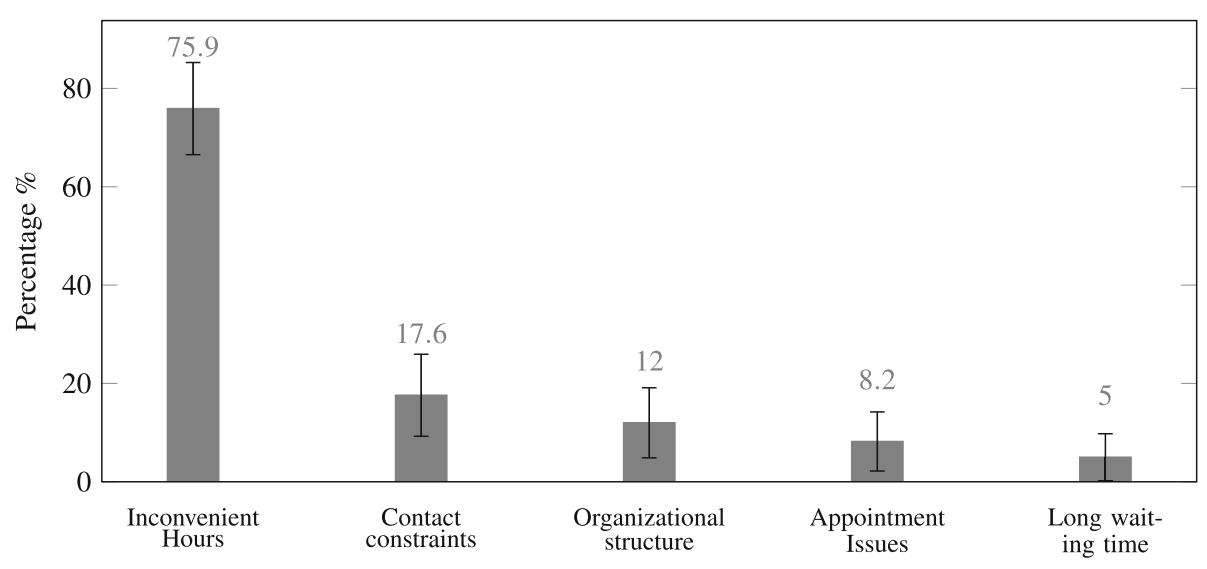

Fig. 6 Barriers related to accommodation amongst the Bakarwals (error bars represent 95\%Cl) 
Table 4 Instrumental probit regression indicating probability of utilization of public health facility

\begin{tabular}{|c|c|}
\hline Variables & Instrumental variable probit \\
\hline \multicolumn{2}{|l|}{ Demand-side characteristics } \\
\hline \multicolumn{2}{|l|}{ Age (ref $=0$ to 14$)$} \\
\hline 15 to 29 & -0.05 \\
\hline 30 to 44 & -0.081 \\
\hline 45 to 59 & -0.005 \\
\hline 60 to 81 & 0.064 \\
\hline \multicolumn{2}{|l|}{ Sex (ref = male) } \\
\hline Female & $-0.129^{* * *}$ \\
\hline \multicolumn{2}{|l|}{ Education (ref = illiterate) } \\
\hline Literate & 0.016 \\
\hline \multicolumn{2}{|l|}{ Group (ref = migrants) } \\
\hline Sedentarized & $0.228^{* * *}$ \\
\hline \multicolumn{2}{|l|}{ Marital status (ref = never married) } \\
\hline Currently married & 0.034 \\
\hline Widowed & -0.089 \\
\hline Divorced & -0.183 \\
\hline \multicolumn{2}{|l|}{ Wealth quintiles (ref $=$ poorest) } \\
\hline Quintile 2 & -0.061 \\
\hline Quintile 3 & $-0.108^{* * *}$ \\
\hline Quintile 4 & $-0.168^{* *}$ \\
\hline Quintile 5 & -0.59 \\
\hline \multicolumn{2}{|l|}{ Whether chronic (ref = yes) } \\
\hline No & $-0.069^{* *}$ \\
\hline Household size & -0.006 \\
\hline \multicolumn{2}{|l|}{ Trust on medical ability (ref = unsatisfactory) } \\
\hline Satisfactory & $0.033^{* *}$ \\
\hline \multicolumn{2}{|l|}{ Supply-side characteristics } \\
\hline \multicolumn{2}{|l|}{ Time taken to reach nearest facility (ref $=1 \mathrm{~h}$ ) } \\
\hline Within $2 \mathrm{~h}$ & -0.054 \\
\hline Within $3 \mathrm{~h}$ & $-0.218^{*}$ \\
\hline More than $3 \mathrm{~h}$ & $-0.381^{* *}$ \\
\hline \multicolumn{2}{|l|}{ Remoteness (ref = non-availability of transport) } \\
\hline Availability of transport within $2-k m$ radius & $0.232^{*}$ \\
\hline Health facility readiness score & $0.118^{* * *}$ \\
\hline Perceived quality score & $0.101^{* *}$ \\
\hline
\end{tabular}

***Significant at $1 \%(p$ value $<0.01),{ }^{* *}$ significant at $5 \%(p$ value $<0.05)$, and ${ }^{*}$ significant at $10 \%(p$ value $<0.10)$

Effect of the demand-side factors: The results of the model reveal that females are less likely to utilize the public health facilities. Also, the sedentarized population is $22.8 \%$ more likely to visit a public health facility compared to the migrant group, significant at $1 \%$ level of significance. Also, people belonging to the richer quintile are significantly less likely to visit a facility as compared to the poorest population who may be visiting the public hospitals more due to the cost constraint in using private facilities. Also, need-based factor of suffering from chronic disease renders the individual more likely to seek care, significant at $5 \%$ level. Also, the people who perceive attitude of workforce to be satisfactory are 3.3\% more likely to seek care in government centres.

Effect of the supply-side factors: There is a negative and significant relationship between the time taken to reach the health facility and utilization. There is $21.8 \%$ less probability of visiting the facility if the travel 
distance is within three hours as compared to travel distance which is within one hour. However, the probability plummets $38.1 \%$ more if the travel distance is increased to more than three hours. Also, the availability of transport within a $2-\mathrm{km}$ radius increases the probability of seeking care by $23.2 \%$. A higher health facility readiness score positively impacts the utilization at $1 \%$ level of significance. A higher score translates to $11.8 \%$ more likelihood of utilizing the facility fostered by positive attitude and more confidence in better functioning centres. Such relationship is also depicted by perceived quality scores, where a percentage increase in perceived quality scores increases the probability of utilization by $10.1 \%$ level.

Results for logit regression ascertaining correlates of catastrophic expenditure in Table 5 signify that as the proportion of elderly people in a household increases, the likelihood of incurring catastrophic expenditure on health also increases by $23.4 \%$ (at $1 \%$ significance level). Also, households with members suffering from chronic disease are $17.5 \%$ more likely to have an incidence of catastrophic payment as compared to households with no chronic case. The richest quintile group has $39 \%$ less probability to suffer from health expenditure-related shocks due to their higher capacity to pay for healthcare. Households seeking treatment from private providers due to high user fee and expensive drugs and diagnostics are $44 \%$ more probable to get hit by catastrophic payments which is highly significant at $1 \%$, whereas seeking care from an informal/traditional healer decreases the probability by $6.7 \%$ at $5 \%$ level of significance. Also, as per the intuitive understanding, those households who

Table 5 Correlates and determinants of catastrophic expenditure on healthcare

\begin{tabular}{ll}
\hline Correlates & Marginal effects \\
\hline Proportion of elderly people in household & $0.234^{* * *}$ \\
Proportion of children in household & 0.112 \\
Members with chronic disease in household & $0.175^{* *}$ \\
Wealth quintile (ref = quintile 1) & \\
Quintile 2 & 0.042 \\
Quintile 3 & -0.116 \\
Quintile 4 & $-0.184^{*}$ \\
Quintile 5 & $-0.391^{* * *}$ \\
Type of facility visited (ref = public) & \\
Private & $0.439^{* * *}$ \\
Informal/traditional & $-0.067^{*}$ \\
Average illness episodes per family & $0.093^{* *}$ \\
Household head without formal education & 0.002 \\
Group (ref = migrants) & \\
Sedentarized & $0.10^{* *}$ \\
\hline
\end{tabular}

***Significant at $1 \%$ ( $p$ value $<0.01)$, ${ }^{*}$ significant at $5 \%$ ( $p$ value $\left.<0.05\right)$, and ${ }^{*}$ significant at $10 \%(p$ value $<0.10)$ suffered more illness episodes incur more expenditure, thereby making them vulnerable. Furthermore, a sedentarized household has 10\% more probability of incurring catastrophic payments as compared to a migratory household, which can be explained partly by the fact that a higher percentage of the sedentarized population seek care when ill as compared to the migratory population who often forgo care and, also, the wealth status of the sedentarized is also less than the migratory, who have more livestock and assets as compared to the sedentarized.

\section{Discussion and conclusion}

Transhumance pastoralism poses unprecedented challenges for the effective delivery and geographic accessibility of health services. The scant literature on delivery of health services and their accessibility for transhumant pastoralists or sedentarized populations suggests there is a colossal difference between the barriers and constraints faced by the mobile population vis-à-vis the sedentarized. Unlike other tribal groups in developing countries, which cite culture/awareness as the major access barrier (Rahman et al. 2012; Office of Registrar General and Census Commissioner GoI Ministry of Home Affairs 2011; Sheik-Mohamed and Velema 1999; Ministry of Social Justice and Empowerment GoI 2008; Sundararajan et al. 2013), the majority of our transhumant pastoralist group reported unavailability of healthcare services as the reason for not seeking care. Another study in the Indian context (Mishra et al. 2015) investigating barriers to access government health services by migrant tribal communities also reveals that more than half of respondents stated non-availability of medicines/ availability of low-cost medicine as the major reason for not utilizing public facilities. For Bakarwals, forays into remote areas in search of pastures also cause an affordability issue compounded by high transportation and time costs. This leaves them with no choice apart from depending on local traditional medicines such as herbs and shrubs. Similar findings have been reported by Yadav et al. (2000) related to the tribals of the Satpura region of India where tribals reside deep in forests with no sufficient medical facility available to them and therefore entirely depend on traditional medicines. Transportation costs take up a significant amount of out-of-pocket expenditure, which is greater than the share of medicinal and diagnostic costs. Most of the inpatient expenditure is financed by the sale of assets and livestock due to the absence of readily available health insurance policies and the lack of awareness regarding them. This imposes a catastrophic burden on the patient, causing them to part from their source of livelihood.

As the lives of pastoralists are closely intertwined with their livestock, convergence of new approaches linking 
human and animal health is gaining momentum. Studies have indicated such an approach as 'One Health' is proven to be effective for service delivery and cost management, as significant cost can be shared by sharing the transport and cold chain. Based on evidence from research and interventions pertaining to the One Health model, the advantages and synergies of such an approach have become evident (Zinsstag et al. 2011; Greter et al. 2014). Such an integrated public health system which includes medical doctors and veterinarians, and such a strategic development framework exploring humans/animals/ecosystems is missing in our study area except for sporadic joint camps organized by the army.

Our facility survey revealed that despite government interventions promising mobile health clinics, the issue of availability persists - provision of healthcare services to transhumant pastoralist tribes is expensive and logistically complicated. Even though population movement patterns are repetitive and predictable, planned interventions fail to take off because transhumant pastoralist movement often occurs to and from remote and obscure locations. Trained medical staff are unenthusiastic about going to the farther reaches due to the lack of monetary incentives to navigate uncharted terrains without the help of accurate maps and reliable transportation. The threat of encountering militancy and violence while commuting in these areas further discourages the delivery of healthcare. The survey also reveals that existing health facilities in the lower altitude reaches meant to cater for the sedentarized groups do not function efficiently - doctors, drugs and equipment are scarcely available and many of these facilities remain inoperative even during working hours. Visiting patients are forwarded to seek care at referral units at the district headquarters, causing gross overcrowding of patients and acute shortage of human resources at the district hospital. This is supported by readiness assessment scores at the district hospital which are lowest for human resources and consumables. These findings resonate with a case study in Kenya (Jillo et al. 2015) where health facilities are often located in urban centres with almost no mobile health facilities to cater for transhumant pastoralists and communities in far-flung regions in the north and semi-arid areas where infrastructure is non-existent. The cost of accessing medical and health facilities in Kenya is also costly and often beyond the reach of many indigenous communities, who may not have the means to travel long distances to purchase certain prescribed drugs that are unavailable in public health facilities. The fact that there are almost no health facilities in close proximity to most indigenous people means that they have to walk long distances even during an emergency, which results in poor health outcomes.
The entire region in our study is grappling with the dearth of private providers. There are hardly any private hospitals/nursing homes/physicians in the area. The pool of private providers is thus comprised of doctors from public hospitals who work part-time as private practitioners and operate in an urban centre in a small defined geographical space. Lack of private providers is reflected in less competition and leads to less efficiency and decreased quality. There is restricted diversity of providers from which patients can choose; this further impedes the quality of care. The health system in the region is impacted due to the skewed doctor-patient ratio and overburdening of existing staff. Very few specialists are available and most of the sanctioned positions are vacant, thereby accentuating the distance travelled by patients for secondary and tertiary care.

In many low- and middle-income countries, pharmacists are often the patients' first point of contact with the healthcare system and their preferred channel for purchasing medicines. The redeeming feature of pharmacies are long opening hours, availability of medicines, geographical accessibility and personal familiarity, but the caveat in this form of drug selling as categorized by the World Health Organization is that they meet the criterion for being irrational consumption of drugs. However, consultation and buying over-the-counter drugs from pharmacists is very popular amongst the study population, partly due to imbued trust in them and flexible payment policy emanating from a community effect. The major reason, although narrated by the community, is the unavailability of free medicines in the public facilities, acting as disincentive to travel longer distances, since as according to the community, the monetary and opportunity cost to seek institutional care outweighs the utility derived by them.

This case study is generalizable to other transhumant pastoralists inhabiting remote rural settings as they also face symptomatic problems such as geographical inaccessibility of health facilities, discriminatory attitudes ingrained in health systems, communication quagmires, supply-side constraints and social exclusion exacerbating their vulnerabilities. Further, to improvise the study, models like the binary integer programming model as in Ndiaye and Alfares (2008) can be formulated by reasearchers in varied settings to determine the optimal number and locations of primary health units to satisfy a seasonally varying demand by harnessing a field of dynamic locations.

\section{Recommendations}

The governing authorities should take steps by providing health facilities during the transhumants' migration, especially to upper altitude reaches. Setting up mobile clinics and community-based services would be helpful 
in inculcating positive health practices and benefits which would also reduce the time and travel costs as well as the costs of service delivery. Proper training in health matters should be provided to the community workforce so that they can take informed decisions. For example, public education and counselling will increase access to information about self-care, when care is needed and where it is available. Focus on long-term improvements in education and awareness opportunities will play a defining role in the health of the Bakarwals. In the short term, progress can be achieved by strengthening and expanding essential health services and promoting more positive attitudes and behaviour. For example, provision of community health insurance would fill the existing gap in distressed financing. Investing in human capital from within the community, e.g. training the transhumant pastoralists to provide a mix of essential health services, is likely an affordable and sustainable alternative.

Further, a participatory and trans-disciplinary approach involving scientists, government authorities, pastoral communities and their representatives is pertinent to empower the community and make them central to decision-making. Such models are increasingly being considered for example in Chad, as through such inter-sectoral and inclusive programmes, mobile pastoralists gave ownership and assumed their responsibilities more easily (Montavon et al. 2013).

Interventions emulating the Ng'adakarin Bamocha model in Kenya which is based on migratory routes of Turkana pastoralists to improve access to maternal and child health services should be promoted as the effectiveness of the model has been established (Jillo et al. 2015). The intervention consisted of strategically locating 20-ft-long freight container clinics along the migratory routes which are operated by a trained community nurse and community health workers providing curative services, immunization referral to level 2 health facilities and community education.

The per capita cost of a satisfactory health service in scattered communities is bound to be high because, at any given time, the number of patients is likely to be small and because of the need for special facilities, such as mobile clinics. There is a need for operational research in order to select the best approaches in terms of appropriateness, practicality and cost-effectiveness (Omar 1992). Aligning with this, governments and aid organizations have been seeking quasi-sedentary solutions to provision of health services to nomads as an interim means of mediating between the mobile and sedentarized population.

It is imperative to install a demographic surveillance system for mobile pastoralists due to the dynamic nature of their operations. This can be facilitated via mobile phone surveillance and health informatics involving real-time mapping of transhumance routes. Implementation of such small-scale interventions in Chad indicated the effectiveness of a mobile demographic surveillance system and GPS tracking in inaccessible and remote settings. Such real-time knowledge on camp locations and populations facilitates health interventions such as vaccine delivery/sensitization, information campaigns and emergency medicines (Jean-Richard et al. 2014). Such real-time follow-up of health indicators allow for tracking of problems more precisely than the conventional reporting system. This system could be used concomitantly for health and demographic surveillance of humans and their livestock. Also, effective communication networks should be established between the nomads and security forces - the army may come to the rescue of thousands of Bakarwals in the higher reaches when sudden climatic disturbances take a severe toll on them and their cattle. In the areas where communication networks are unperturbed, a telemedicine centre for direct evaluation or specialist for video conferencing can be established to fill in the access gap especially for specialized care.

\section{Endnotes}

${ }^{1}$ Instrumental variable (IV) probit fits probit models where one or more of the regressors are endogenously determined using the maximum likelihood estimation. An instrumental variable for the regressor is valid and generates consistent parameter estimates only under two crucial conditions - when an instrument is significantly correlated with the explanatory variable and uncorrelated with the error term.

\section{Additional file}

Additional file 1: Supplementary document. (PDF 31547 kb)

Acknowledgements

We would like to thank Dr. Javaid Rahi, historian, writer and National Secretary of Tribal Research and Cultural Foundation, for his guidance and logistic support.

\section{Funding}

There is no external funding involved in the project.

Availability of data and materials

Data collection is done through primary survey and is available upon request.

Authors' contributions

VRV is involved in conceptualizing the research and its methodology, conducted the field work and analysis and led the writing of the manuscript and revisions. SG co-led the conceptualization of project, conducted the field work and co-led the writing of the draft of the manuscript. UD participated in the methodological design and assisted in revising the original manuscript. All authors read and approved the final manuscript.

Ethics approval and consent to participate

The protocol for this study has been approved by the ethical committee of Indian Institute of Technology Madras. All human subjects in the study were 
asked for their consent, and they had provided their consent before the data collection. Both oral and written consent was obtained from the community leaders and tribal Jirga council for the household survey whereas required permissions were obtained from district health authorities to conduct the health facility survey.2009

\section{Consent for publication}

Not applicable

\section{Competing interests}

The authors declare that they have no competing interests.

\section{Publisher's Note}

Springer Nature remains neutral with regard to jurisdictional claims in published maps and institutional affiliations.

\section{Received: 10 October 2018 Accepted: 3 January 2019}

Published online: 30 January 2019

\section{References}

Andersen, R.M. 1995. Revisiting the behavioral model and access to medical care: Does it matter? Journal of Health and Social Behavior 36 (1) : 1-10.

Anselmi, L., M. Lagarde, and K. Hanson. 2015. Health service availability and health seeking behaviour in resource poor settings: Evidence from Mozambique. Health Economics Review 5 (1): 26.

Bhasin, V. 2011. Settlements and land-use patterns in the Lepcha Reserve-Dzongu zone in the Sikkim Himalaya, India. Journal of Biodiversity 2 (1): 41-66.

Bhasin, V. 2013. Pastoralists of Himalayas. Journal of Biodiversity 4 (2): 83-113.

Creswell, J.W., R. Shope, V.L. Plano Clark, and D.O. Green. 2006. How interpretive qualitative research extends mixed methods research. Research in the Schools 13 (1): 1-11.

Dangwal L, Singh T, Singh A (2014) Exploration of wild edible plants used by gujjar and bakerwal tribes of district rajouri (j\&k), india. Journal of Applied and Natural Science 6(1):164-169.

Greter, H., V. Jean-Richard, L. Crump, M. Béchir, I.O. Alfaroukh, E. Schelling, B. Bonfoh, and J. Zinsstag. 2014. The benefits of 'one health' for pastoralists in Africa. Onderstepoort Journal of Veterinary Research 81 (2): 1-3.

Grossman, M. 2000. The human capital model. In Handbook of health economics, vol. 1, 347-408. Elsevier BV.

Jean-Richard, V., L. Crump, D. Moto Daugla, J. Hattendorf, E. Schelling, and J. Zinsstag. 2014. The use of mobile phones for demographic surveillance of mobile pastoralists and their animals in Chad: Proof of principle. Global Health Action 7 (1): 23209.

Jillo, J.A., P.O. Ofware, S. Njuguna, and W. Mwaura-Tenambergen. 2015. Effectiveness of Ng'adakarin Bamocha model in improving access to antenatal and delivery services among nomadic pastoralist communities of Turkana West and Turkana North Sub-Counties of Kenya. The Pan African Medical Journal 20: 403

Joseph, A.E., and D.R. Phillips. 1984. Accessibility and utilization: Geographical perspectives on health care delivery. London: Harper \& Row.

Khatana, R.P. 1992. Tribal migration in Himalayan frontiers: Study of Gujjar Bakarwal transhumance economy. Gurgaon: Vintage Books.

Kumar, A., and N. Kumar. 1998. Gujjar Bakerwal-the ecofriendly tribals of Jammu and Kashmir since centuries. Bull Ind His Med, 28 : 139-145.

Kumar, S., E.A. Dansereau, and C.J. Murray. 2014. Does distance matter for institutional delivery in rural India? Applied Economics 46 (33): 4091-4103.

McKinlay, J.B. 1972. Some approaches and problems in the study of the use of services - an overview. Journal of Health and Social Behavior 3(2):115-52.

Ministry of Social Justice \& Empowerment Gol. 2008. National Commission for Denotified, Nomadic and Semi-Nomadic Tribes. http://socialjustice.nic.in/ writereaddata/UploadFile/NCDNT2008-v1\%20(1).pdf

Mishra, S., Y.S. Kusuma, and B.V. Babu. 2015. Migration and health-care access: Barriers to access government health services by migrant tribal community living in an eastern Indian city. International Journal of Medical Science and Public Health 4 (1): 101-108

Montavon, A., V. Jean-Richard, M. Bechir, D. Daugla, M. Abdoulaye, R. Bongo Naré C. Diguimbaye-Djaibé, I. Alfarouk, E. Schelling, K. Wyss, et al. 2013. Health of mobile pastoralists in the sahel-assessment of 15 years of research and development. Tropical Medicine \& International Health 18 (9): 1044-1052.

Ndiaye, M., and H. Alfares. 2008. Modeling health care facility location for moving population groups. Computers \& Operations Research 35 (7): 2154-2161.
Office of Registrar General \& Census Commissioner Gol Ministry of Home Affairs. 2011. Population enumeration data, census 2011. http://www.censusindia. gov.in/2011census/population_enumeration.html.

Omar, M. 1992. Health care for nomads too, please. World Health Forum 13 (4): 307-310 http://europepmc.org/abstract/MED/1466726.

Penchansky, R., and J.W. Thomas. 1981. The concept of access: definition and relationship to consumer satisfaction. Medical Care 19(2): 127-140.

Phillips, D.R., et al. 1990. Health and health care in the Third World. Longman Scientific and Technical. Harlow.

Rahman, S.A., T. Kielmann, B. McPake, and C. Normand. 2012. Healthcare-seeking behaviour among the tribal people of Bangladesh: Can the current health system really meet their needs? Journal of Health, Population, and Nutrition 30 (3): 353.

Rashid A (2013) Ethnomedicinal plants used in the traditional phytotherapy of chest diseases by the gujjarbakerwal tribe of district rajouri of jammu \& kashmir state. Inter- national Journal of Pharmaceutical Sciences and Research 4(1):328-333.

Sheik-Mohamed, A., JP. Velema. 1999. Where health care has no access: The nomadic populations of sub-Saharan Africa. Tropical Medicine \& International Health 4(10):695-707.

Sundararajan, R., Y. Kalkonde, C. Gokhale, P.G. Greenough, and A. Bang. 2013. Barriers to malaria control among marginalized tribal communities: A qualitative study. PLOS ONE 8 (12): e81966.

Teddlie, C., and A. Tashakkori. 2003. Major issues and controversies in the use of mixed methods in the social and behavioral sciences, Handbook of mixed methods in social \& behavioral research, 3-50. Thousand Oaks, CA: Sage.

Yadav, S., S. Patil, et al. 2000. Traditional medicines and healthcare system of tribals of Satpuda Region, Maharashtra State. New Botanist 27 (1/4): 51-65.

Zinsstag, J., M. Ould Taleb, and P. Craig. 2006. Health of nomadic pastoralists: New approaches towards equity effectiveness. Tropical Medicine \& International Health 11 (5): 565-568.

Zinsstag, J., E. Schelling, D. Waltner-Toews, and M. Tanner. 2011. From "one medicine" to "one health" and systemic approaches to health and wellbeing. Preventive Veterinary Medicine 101 (3-4): 148-156.

\section{Submit your manuscript to a SpringerOpen ${ }^{\circ}$ journal and benefit from:}

- Convenient online submission

- Rigorous peer review

- Open access: articles freely available online

- High visibility within the field

- Retaining the copyright to your article

Submit your next manuscript at $>$ springeropen.com 